\title{
Surgical Management of High Grade Gynecomastia: Combination of Liposuction, Glandular Resection and a Circumareolar Skin Reduction
}

\author{
AYMAN FIKRY, M.D. and MOHAMMAD NASR, M.D. \\ The Department of General Surgery Plastic \& Reconstructive Surgery Unit, Faculty of Medicine, Zagazig University
}

\begin{abstract}
Background: Gynecomastia is defined as an excessively developed male breast to the extent it resembles the female one. Emotional discomfort and social embracement motivate the patients to seek a medical advice, to restore the masculine breast shape. In high grade gynecomastia, the contributing factors are excess redundant skin, fibro-glandular tissue and abundant adiposity, each component should be considered separately in the patient's surgical plan. Various surgical procedures were succeeded to correct this deformity but with drawbacks such as residual unsightly scar, or contour irregularities.
\end{abstract}

Objectives: Were to treat high grades of gynecomastia with a multifaceted procedure; by combining liposuction, glandular excision together with excess skin resection through circumareolar concentric approach.

Aim: This study has evaluated that procedure as regard technical refinements, early and late complications and aesthetic outcome.

Method: In this case series, eighteen healthy male patients who had bilateral gynecomastia, had undergone correction of their breast deformity with that multifaceted procedure between January 2016 and June 2017, their ages ranged from [1761 years old, with mean \pm 30.94$]$.

Results: All patients were satisfied with the results except one patient who had undergone reoperation. The early complication rate was $27.7 \%$; it was consistent with other series. The follow-up aesthetic evaluation scale showed that $65 \%$ of patients with very good result, $22 \%$ of patients with good result, $17 \%$ patients with average result, and only one patient had poor result.

Conclusion: This combination had succeeded to address the contributing causes of severe gynecomastia. The problems of excess and displaced tissues were properly dealt with through circumareolar approach to achieve a pleasant scar confined to the areola with flat male chest.

Key Words: Gynecomastia surgery - Liposuction - Circumareolar skin resection - Aesthetic outcome.

\section{INTRODUCTION}

Gynecomastia refers to an abnormal and evident increase in the volume of male breast, mimicking that of females $[\mathbf{1 , 2}]$. The development of such feminine breast shape in gynecomastia patients severely affects social life and may cause significant emotional distress and embarrassment, particularly in adolescents and young men [3].

Regarding to the etiological factors, gynecomastia could be either physiological, or pathological on the basis of endocrinal imbalance, and when no specific cause could be found, it is diagnosed by exclusion as idiopathic, which is being the most common one [1]. Gynecomastia is considered as the most common benign problem affecting male breast, it occurs in about $30 \%$ of middle-aged males and increases with old age due to decline in testosterone level [4]. Also gynecomastia could be categorized to (true) when excess glandular tissue predominates, pseudo-gynecomastia in case of excess adipose tissue, or (mixed type) [5].

Spontaneous regression or an effective nonsurgical treatment is only theoretically possible in early gynecomastia induced by pubertal hormonal fluctuation with recent glandular proliferation, which has not produced any skin ptosis [6]. In persistent longstanding cases for over a year, irreversible process of fibrosis and hyalinization of the loose peri-ductal tissue and the surrounding stroma causing a glandular hypertrophy, which once it has established in it cannot regress [7], and so in most cases it requires surgical treatment.

The challenging issues in high grades of gynecomastia with large ptotic breasts are the presence of excess redundant skin, hypertrophied glandular 
tissue, and abundant adipose tissue. In such cases, this skin has lost its elastic properties, mainly skin retraction, while the excess glandular tissue is located mainly subjacent to nipple areola complex [NAC] which is firmer than the surrounding fatty tissue, resulting in distended and displaced NAC $[8,9]$.

The ideal surgical approach aimed not only to reduce the breast mound size but also to obtain an accepted breast shape and restore masculine chest contour by resecting excessive glandular tissue, fatty tissue and excess skin, reducing and adequately relocating the NAC, and removing the submammary fold while avoiding residual unsightly postoperative scarring to the chest $[9,10,11]$.

The surgical methods used for severe gynecomastia were ranging from older techniques such as reduction mammoplasty with free grafting of the NAC, to currently used one as modified breastreduction techniques either (no vertical scar or Tshaped scar pattern), or subcutaneous mastectomy with peri-areolar concentric skin excision [Benelli type] [12], although these procedures might succeed in reducing the breast size [13], but a high rate of unacceptable outcomes had observed, mainly because of the unhidden residual scars, contour irregularities, residual redundancy, and NAC deformities [12].

The purpose of this study was to evaluate the combination of liposuction, glandular excision and periareolar concentric skin resection technique in males with high grade gynecomastia as regard technical refinements and outcome, in the hope of reshaping the breast and achieving an ideal aesthetic result of this condition.

\section{PATIENTS AND METHODS}

The present study was an prospective interventional study (pre-post), it was carried out on 18 healthy male patients who had bilateral gynecomastia persistent at least for more than one year, between January 2016 and June 2017, their ages ranged from [17-61 years old, with mean \pm 30.94 ], while patients who have any pathological etiology for their gynecomastia (after consultation of endocrinologist, and hormonal assay) or massive weight reduction with or without bariatric surgery, or recent gynecomastia, were excluded from the study.

Preoperatively, the included patients were classified as grade IV gynecomastia according to ASPS [American society of plastic surgeons] scale [14] adjusted from Simon et al., [15] classification; it classifies breasts based on morphology and volume into four grades (Table 1).
Table (1): ASPS Gynecomastia scale.

\begin{tabular}{ll}
\hline Grade I & $\begin{array}{c}\text { Small breast enlargement with localized button } \\
\text { of tissue that is concentrated around the } \\
\text { areola. }\end{array}$ \\
Grade II & $\begin{array}{l}\text { Moderate breast enlargement exceeding areola } \\
\text { boundaries with edges that are indistinct from } \\
\text { the chest. }\end{array}$ \\
Grade III & $\begin{array}{l}\text { Moderate breast enlargement exceeding areola } \\
\text { boundaries with edges that are distinct from } \\
\text { the chest with skin redundancy present. }\end{array}$ \\
Grade IV & $\begin{array}{l}\text { Marked breast enlargement with skin redun- } \\
\text { dancy and feminization of the breast. }\end{array}$
\end{tabular}

Patients were selected from the outpatient clinic of Plastic Surgery Unit of Zagazig University Hospitals. All participating patients were informed about the steps of the procedure and possible complications and were consented. The patients were evaluated for evident excess glandular tissue by clinical examination and ultrasonography.

\section{Operational design:}

Preoperative marking was done while the patient in the upright standing position, the entire breast mound, plus to the chest areas lateral, medial and inferior to pectoralis muscle and also epigastrium area were outlined. Marking the inframammary crease and breast median and NAC boundary (the inner circle), in case of large NAC diameter; it was reduced to $2.5-3 \mathrm{~cm}$ in diameter (the average diameter of male areola is ranging from 2.67 to $2.8 \mathrm{~cm}$ in the anatomical studies [16].

The excess skin was outlined in a concentric circumareolar manner (the outer circle), depending on the size and shape of the breast, or determined by the following equation (the radius of outer circle equals the sum of adding [0.8 $\mathrm{x}$ radius of the areola] to the radius of the areola) [17], so it ranges from $2 \mathrm{~cm}-2.5 \mathrm{~cm}$ in width from the edge of inner circle. In hairy patients, shaving was limited only to the marked concentric area (Figs. 1A,2A).

\section{Operational procedure:}

The procedure was carried out under general anesthesia. At first, all the above outlined areas was infiltrated with tumescent solution, through a $2-3 \mathrm{~mm}$ skin incision was done at the middle of inframammary crease, Mercedes liposuction cannulas $3 \mathrm{~mm}$ cannula was introduced. Liposuction of adipose tissue was performed in two planes; deeper and superficial to breast parenchyma until evident reduction of the breast volume, contour remodeling, and parenchymatous tissue freeing (assessed by pinch test). After liposuction, the 
residual palpable glandular tissue was located mostly in the sub-areolar area.

The concentric circumareolar doughnut shaped skin ring was de-epithelialized with care to avoid injury or damage to the sub dermal blood flow to NAC, Then the glandular tissue is entirely excised through a small transdermal incision lower down at de-epithelized area between 5 to 7 o'clock position leaving only enough disk of tissue attached underneath the areola to a prevent development a depressed or ischemic areola, then NAC was relocated to a higher level at mid humerus level by suturing it to pectoralis fascia, just medial to the mid-clavicular line (Fig. 3A).

After glandular tissue has been completely removed, the consistency, uniformity of the mammary area and any remaining lumps of tissue are checked by pinching the skin, additional liposuction could eventually be done; by using a thin $2 \mathrm{~m}$ cannula to smooth out any contour irregularities, especially at the margins of the pectoral area and along the anterior axillary pillar.

After ensuring proper hemostasis, the breast pocket is irrigated with saline, a suction drain was coming out from the same stab for liposuction, left for the first 24-48 hours, then the trans dermal incision was closed with interrupted 3-0 Vicryl sutures, then an interrupted subcuticular suture of 3-0 Vicryl suture was used to closely approximate the external skin with the internal areola in a serial bisecting sutures. Next, a 4-0 polyproproline running subcuticular suture was placed for better approximation of skin edges (Fig. 3B).

A compressive garment is worn for 6-8 weeks, and suture removal after two weeks (Figs. 1,2,4,5). The only suspicious resected glandular tissue (any nodularity, or calcifications) was sent to histopathological examination.

Follow-up examinations: The follow-up period was up to 6 months after the surgery. Postoperative analysis included pre and postoperative photographic documentation, early and late post-operative complications, and aesthetic result by the use of the qualitative evaluation scale by Kasielska and Antoszewski [18] (Table 2).

The Final aesthetic result was as follow (on the basis of the sum of the points): 'Very good' malelike breast 0-1 point, 'Good' male-like breast between $>1$ to 2 points, 'Average' reoperation to be considered $>2-4$ points, and 'poor', reoperation needed $>4-8$ points.
Table (2): Evaluation scale of the cosmetic results after gynecomastia surgical treatment.

\begin{tabular}{lll}
\hline Item & Points \\
\hline Breast size & - Male sized & 0 \\
& - Between 0 and 2 & 1 \\
& - Female sized, & 2 \\
Breast Symmetry & - Symmetrical Well positioned & 0 \\
& - Between 0 and 2 & 1 \\
\multirow{2}{*}{ NAC Shape and } & - Asymmetrical Malpositioned & 2 \\
symmetry & - Symmetrical, and good projection & 0 \\
& - Between 0 and 2 & 1 \\
Scar Visibility & - Asymmetrical, and deformed & 2 \\
& - Blmost invisible & 0 \\
& - Visible, unaesthetic & 1 \\
\hline
\end{tabular}

\section{RESULTS}

The average amount of lipoaspirate was 450 $\mathrm{ml}$ per side (range $=350-550 \mathrm{ml}$ ), the early perioperative complications were $27.7 \%$; two cases of haematoma was evacuated from drain site, two cases with seroma formation, which conservatively managed by needle aspiration and pressure garments and one case with partial necrosis of areolar edge; perhaps due to excessive removal of tissues beneath the areola, (no further management was done to this areola) (Fig. 1B). While the late postoperative complication rate was $33.3 \%$, most frequent complications occurred were saucer-like deformity in two cases (Table 3). There were 2 cases with suspicious excised biopsies, which were free of malignancy by histopathological examination.

Table (3): Postoperative complications in the examined group of grade III gynecomastia $(n=18)$.

\begin{tabular}{|c|c|c|}
\hline & No. & $\%$ \\
\hline \multicolumn{3}{|l|}{ Early: } \\
\hline - Hematoma & 2 & 11.1 \\
\hline \multicolumn{3}{|l|}{ - NAC necrosis } \\
\hline • Partial & 1 & 5.5 \\
\hline - Complete & 0 & 0 \\
\hline - Wound infection & 0 & 0 \\
\hline - Seroma & 2 & 11.1 \\
\hline Total & 5 & 27.7 \\
\hline \multicolumn{3}{|l|}{ Late: } \\
\hline - Asymmetries between breasts & 1 & 5.5 \\
\hline - Residual gynecomastia (under resection) & 0 & 0 \\
\hline - Persistence of inframammary fold & 1 & 5.5 \\
\hline - Contour irregularities & 1 & 5.5 \\
\hline $\begin{array}{l}\text { - Saucer-like deformity } \\
\text { (over resection under areola) }\end{array}$ & 2 & 11.1 \\
\hline - Prolonged hypothesia & 0 & 0 \\
\hline - Hypertrophic scar & 1 & 5.5 \\
\hline Total & 6 & 33.3 \\
\hline
\end{tabular}


According to qualitative evaluation scale; there were very good result in 10 patients $(56 \%)$, good result in 4 patients (22\%), average result in 3 patients

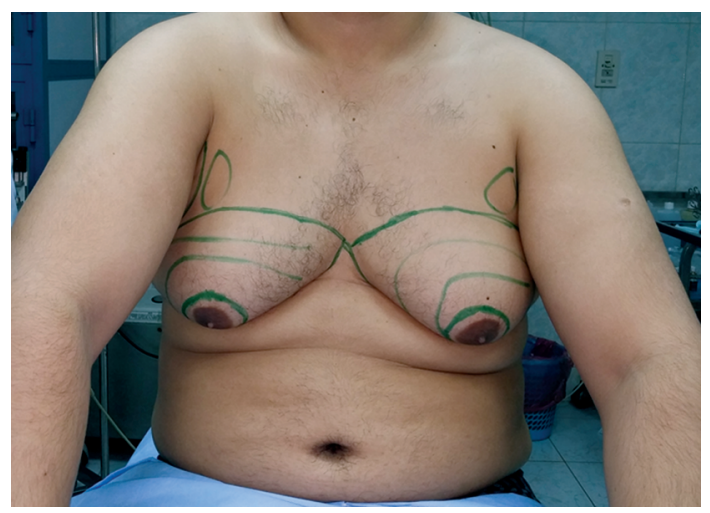

Fig. (1A): Preoperative markings-frontal view.

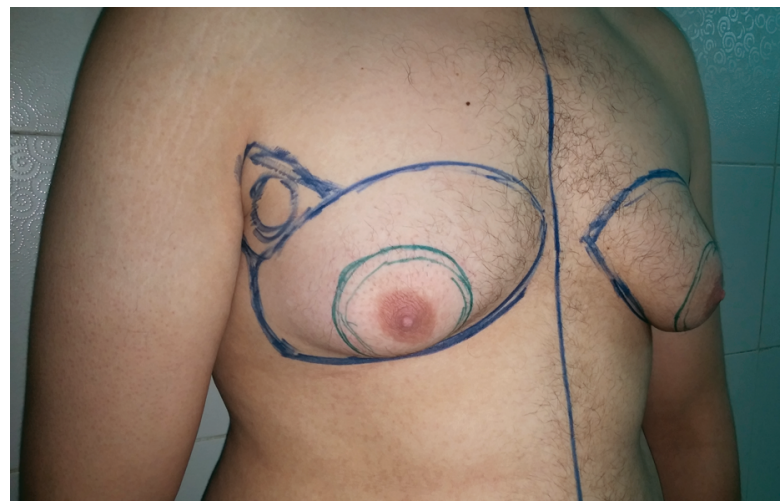

Fig. (2A): Preoperative markings-oblique view.

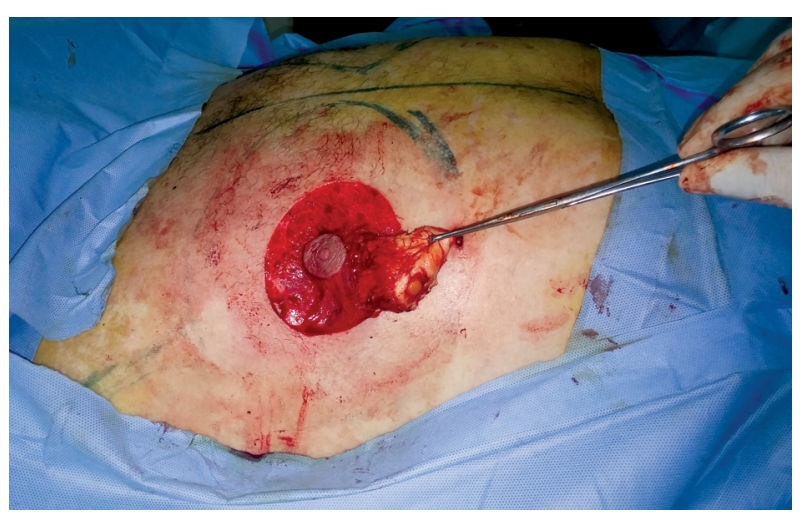

Fig. (3A): De-epithelialized circumareolar area, with glandular excision.
(17\%) and 1 patient (5\%) with poor result, it was due breast asymmetry between both sides and so revisional surgery was indicated for this patient.

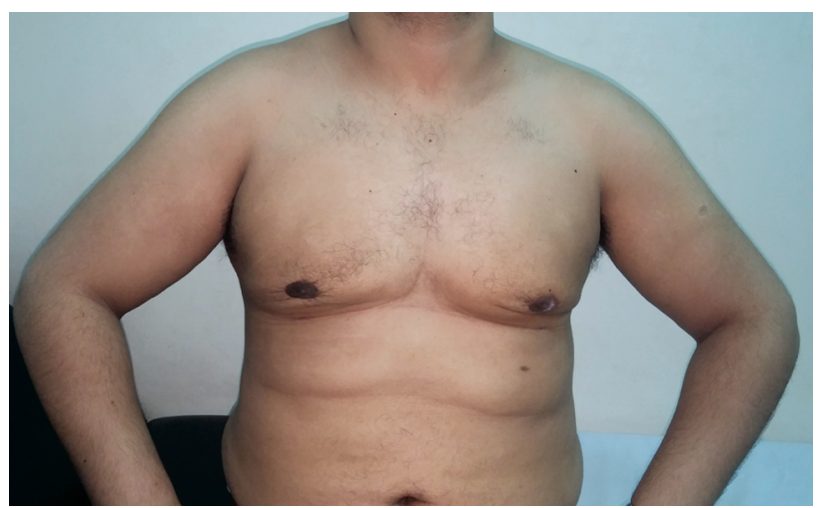

Fig. (1B): Postoperative view 3 months later, partial necrosis of left areola.

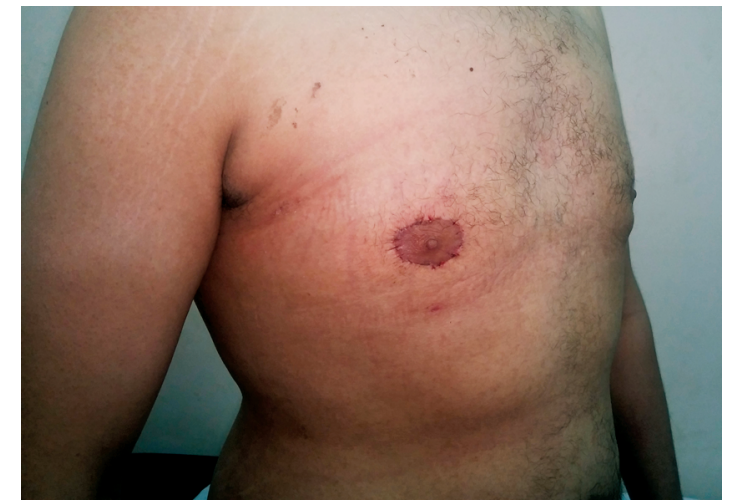

Fig. (2B): Postoperative view 6 weeks later.

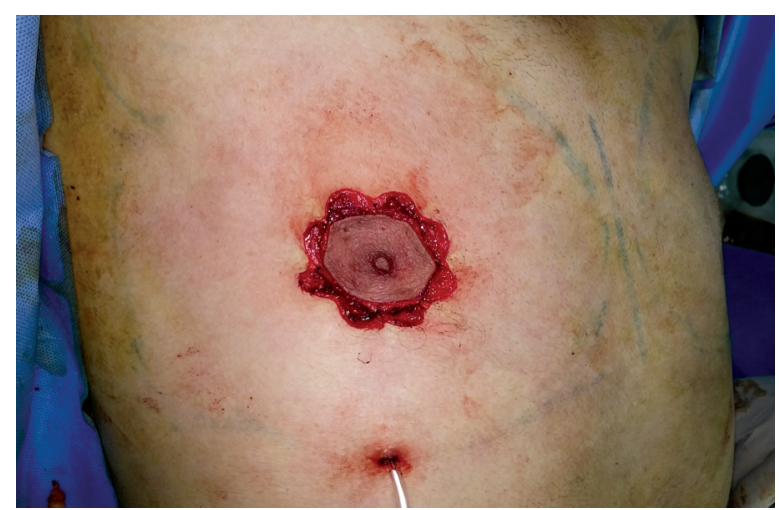

Fig. (3B): Serial bisecting stitch closure, drainage through same stab of liposuction cannula. 


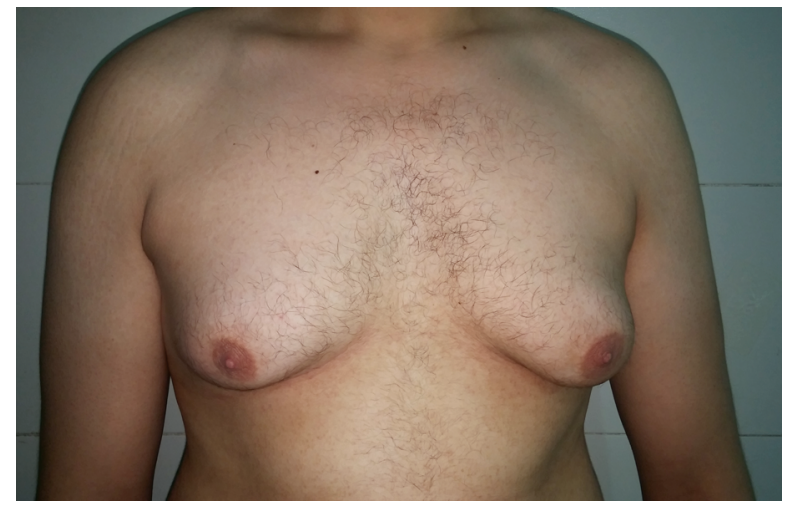

Fig. (4A): Preoperative front view.

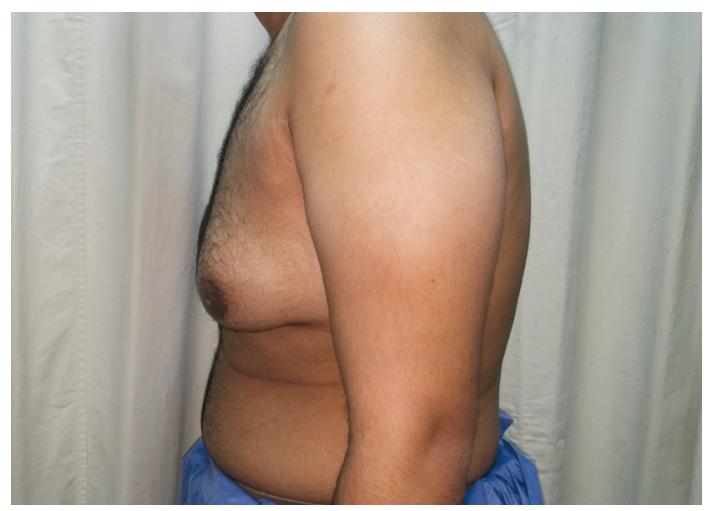

Fig. (5A): Preoperative lateral view.

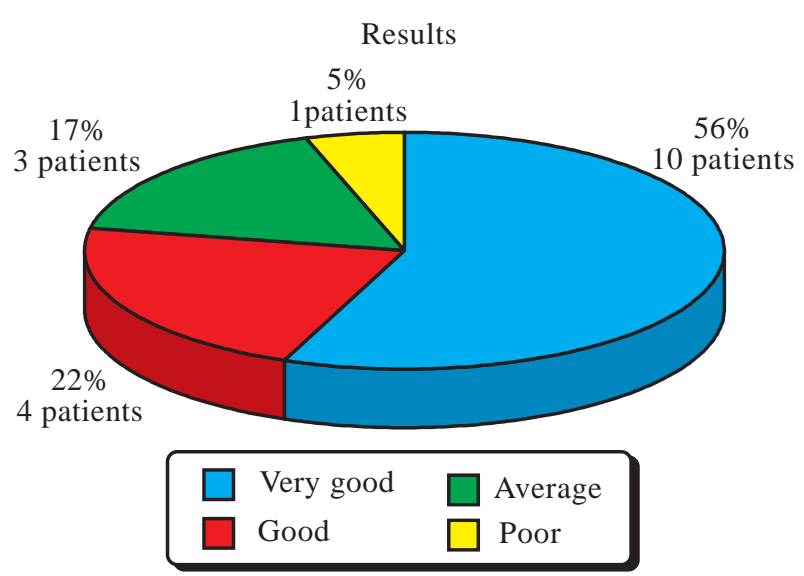

Fig. (6): Pie chart illustrates post-operative aesthetic outcome.

\section{DISCUSSION}

It is a great challenge to achieve a very good or even a good aesthetic outcome in patients with high grade gynecomastia [18]. The problem to solve in severe gynecomastia is not localized accumulation of glandular or adipose tissues but how to deal with major skin redundancy and how the postoperative residual scarring would be [6].

In the presence of such issues, the possibility of simple corrective procedures such as liposuction

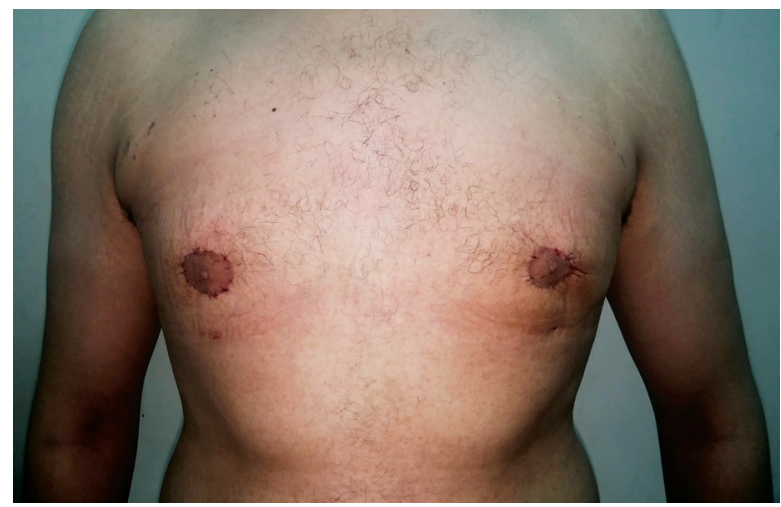

Fig. (4B): Postoperative view 6 weeks later.

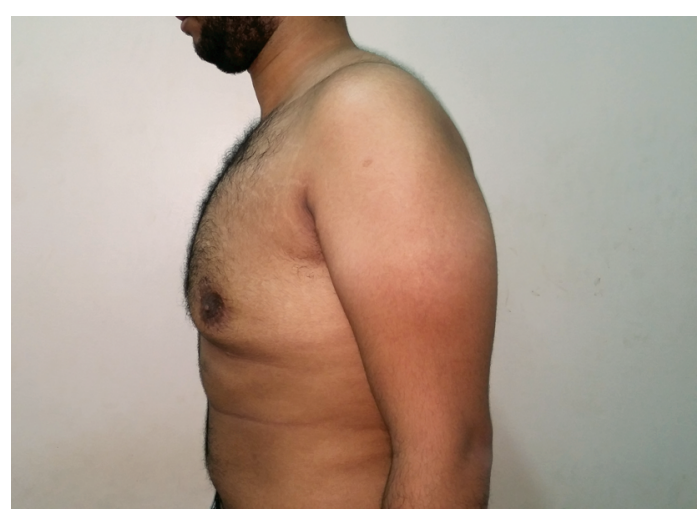

Fig. (5B): Postoperative lateral view 6 months later.

or skin sparing techniques is negated. Although liposuction is considered a milestone in the modern era of gynecomastia surgery, the fulcrum of treatment is not liposuction alone and it would not be sufficient to obtain a good flattening of the chest without skin excision [2,6].

Nowadays, surgery that combines liposuction with skin, and glandular excision techniques is necessary to avoid an inadequate result and the burden of a reoperation $[\mathbf{1 9 , 2 0 , 2 1 ]}$. Besides it is advocated for a finest aesthetic result that the scars should be confined to the periareolar area [6].

In the current study, we agreed with cavina [2], sharker et al., [11], and Gusenoff et al., [22], that a more optimum result could be accomplished by a comprehensive approach to include the aesthetic units outside the breast mound, so synchronous liposuction of the chest areas and epigasteric area was done in all cases. The entry point of liposuction cannula at the inframammary line allowed crisscross suction of the same and contralateral breast, chest, epigasteric area and freeing the inframammary fold from its attachment to the pectoralis fascia.

As regard glandular excision, we agreed with Cannistra et al., [23], that preliminary liposuction 
step greatly facilitates excision of isolated retroareolar glandular tissue through a small transdermal cutaneous incision, in our study an incision between 5 to 7 o'clock was quite enough to ensure subcutaneous dissection of residual hypertrophied glandular tissue with proper hemostasis which was helped by subcutaneous tunnelization by liposuction cannula.

In the current study, the transdermal incision was done lower down between 5 to 7 o'clock position in the de-epithelized area, we had followed the recommendations proposed by Schlenz et al., [24] in their an anatomic study, that skin incisions at the medial edge of the areola should be avoided, as they showed that the medial innervation of the NAC by the $3^{\text {rd }}$ and $4^{\text {th }}$ anterior cutaneous branch, took a "superficial" course within the subcutaneous tissue to reach the medial areolar edge. This has been also extrapolated by the results of Cannistra et al., [23], who reported loss of areolar sensitivity in $10 \%$ of fifty eight patients managed by periareolar incision and double dermal areolar pedicle [incisions were between 2 to 4 o'clock and 8 to 10 o'clock].

As regard the circumareolar incision we found that it is a suitable modality to deal with excess redundant skin, also excessively large NAC got benefit from this excision by reducing its diameter, but excessive skin resection might lead to place too much tension on the suture line with subsequent a greater potential of early wound dehiscence or late scar broadening or hypertrophic scarring, we encountered hypertrophic scarring occurred in one case, managed with topical silicone preparations, it supposed to be due to excessive skin resection. The periareolar scar might be looked wrinkled in the early postoperative period but it improved spontaneously with time, this is agreed with several authors such as Cordova and Moschella [6], Sarkar et al., [11] and Li et al., [25].

As regard complications, early complication rate was $27.7 \%(5 / 18)$ in our series and the revision rate was $5.5 \%$. Other series of management of high grade gynecomastia with liposuction and concentric circumareolar skin excision revealed complication rates ranging from $10 \%$ of fifty eight cases with Cannistra et al., [23], $16.6 \%(1 / 6)$ cases with li et al., [25], 25\% (3/12) with Sarkar et al., [11], to $29.6 \%$ (8/27) with Ibrahim [13], The most common early complication in this study was hematoma and seroma which was consistent with other series.

Finally, we evaluated our results by using an objective scale, it might be claimed that this scale depends on the subjective evaluation by the surgeon. While in the other studies the outcomes are mostly evaluated subjectively by a patient questionnaire or by the surgeon. We believe it might be more beneficial to use one unified scheme for outcome assessment [18].

Conclusion: The strategy of gynecomastia surgery is advocated to combine more than one procedure, and to be designed specifically to address those characterizing problems in severe gynecomastia cases, through doing liposuction for the fatty component, direct excision of the glandular component, and resection of the excess skin, to achieve a flat male shaped chest with pleasant concealed scar at the periphery of areola.

\section{REFERENCES}

1- Morselli P.G. and Morellini A.: Breast reshaping in gynecomastia by the "pull-through technique": Considerations after 15 years. Eur. J. Plast. Surg., 35: 365-371, 2012.

2- Cavina C.: Gynecomastia. In International Textbook of Aesthetic Surgery. Scuderi N, Toth BA. (Eds.). () Springer Berlin Heidelberg, 285-294, 2016.

3- Mentz H.A., Ruiz-Razura A., Newall G., Patronella C.K. and Miniel L.A.: Correction of Gynecomastia Through a Single Puncture Incision. Aesth. Plast. Surg., 31: 244$249,2007$.

4- Ghnnam W.M.: Gynaecomastia Surgery: Should it be Individualized?. J. Cutan. Aesthet. Surg., 7 (2): 116-117, 2014.

5- Wallace A.M.: Gynecomastia In: Evans GRD (ed) Operative plastic surgery McGraw-Hill, New York, 686-697, 2000.

6- Cordova A. and Moschella F.: Algorithm for clinical evaluation and surgical treatment of gynaecomastia, Journal of Plastic, Reconstructive \& Aesthetic Surgery, 61: 41-49, 2008.

7- Nicolis G.R., Modlinger R.S. and Gabrilove J.L.: A study of the histopathology of human gynaecomastia. J. Clin. Endocrinol. Metab., 32: 173-178, 1971.

8- Pérez E.H., Khawaja H.A. and Seijo-Cortes J.A.: Liposuction for Gynecomastia in Liposuction-Principles and Practice. Shiffman M.A., Di Guiseppe A (Eds.), 68:460464, 2006.

9- Thiénot S., Bertheuil N., Carloni R., Méal C., Aillet S., et al.: Postero-Inferior Pedicle Surgical Technique for the Treatment of Grade III Gynecomastia, Aesth Plast. Surg., 2017, quoted from: Hage J.J., Van Kesteren P.J. Chestwall contouring in female-to-male transsexuals: Basic considerations and review of the literature. Plast. Reconstr. Surg., 96 (2): 386-391, 1995.

10- Huang T.T., Hidalgo J.E. and Lewis S.R.: A Circumareolar Approach in Surgical Management of Gynecomastia. Plast Reconstr Surg., 69 (1): 35-40, 1982.

11- Sarkar A., Bain J., Bhattacharya D., Sawarappa R., Munian K., Dutta G., et al.: Role of Combined Circumareolar Skin Excision and Liposuction in Management of High 
grade Gynaecomastia. J. Cutan. Aesthet. Surg., 7 (2): 112-116, 2014.

12- Fruhstorfer B.H. and Malata C.M.: A systematic approach to the surgical treatment of gynaecomastia. Br. J. Plast. Surg., 56: 237-246, 2003.

13- Ibrahiem S.M.: Severe gynecomastia, new technique using superior pedicle NAC flap through a circumareolar approach, Breast. surgery, Ann. Plast. Surg., 76 (6): 645$651,2016$.

14- American Society of Plastic Surgeons ASPS recommended Insurance coverage criteria for third-party payers. http://www. plasticsurgery.org/Documents/medicalprofessionals/health-policy/insurance/GynecomastiaInsurance-Coverage.pdf, 2002.

15- Simon B.E., Hoffman S. and Kahn S.: Classification and surgical correction of gynecomastia. Plast. Reconstr. Surg., 51: 48-52, 1973.

16- Holman O., Badani E., Wolf Y. and Hauben D.J.: Appropriate location of the nipple-areola complex in males. Plast. Reconstr. Surg., 108 (2): 348-351, 2001.

17- Davidson B.A.: Concentric circle operation for massive gynecomastia to excise the redundant skin. Plast. Reconstr. Surg., 63 (3): 350-355, 1979.

18- Kasielska A. and Antoszewski B.: Surgical management of gynecomastia, an outcome analysis, breast surgery. Ann. Plast. Surg., 71 (5): 471-475, 2013.
19- Tashkandi M., Al-Qattan M.M., Hassanain J.M., Hawary M.B. and Sultan M.: The surgical management of highgrade gynecomastia. Ann. Plast. Surg., 53 (1): 17-20 (discussion 21), 2004.

20- Lapid O. and Jolink F.: Surgical management of gynecomastia: 20 years' experience. Scand. J. Surg., 103: 41-5, 2013.

21- Qutob O., Elahi B., Garimella V., Ihsan N. and Drew P.J.: Minimally invasive excision of gynaecomastia - a novel and effective surgical technique. Ann. R. Coll. Surg. Engl., 92: 198-200, 2010.

22- Gusenoff J.A., Coon D. and Rubin J.P.: Pseudogynecomastia after massive weight loss: Detectability of technique, patient satisfaction, and classification. Plast. Reconstr. Surg., 122: 1301-1311, 2008.

23- Cannistra C., Piedimonte A. and Albonico F.: Surgical treatment of gynecomastia with severe ptosis: periareolar incision and dermal double areolar pedicle technique. Aesth. Plast. Surg., 33: 834-837, 2009.

24- Schlenz I., Kuzbari R., Gruber H., and Holle J.: The Sensitivity of the Nipple-Areola Complex: An Anatomic Study, Plast. Reconstr. Surg., 105 (3): 905-909, 2000.

25- Li C.C., Fu J.P., Chang S.C., Chen T.M. and Chen S.J.: Surgical Treatment of Gynecomastia Complications and Outcomes, Breast Surgery, Ann. Plast. Surg., 69 (5): 510$515,2012$. 